\title{
Mutĝ̣wğ sith
}

\section{JURNAL}

HUKUM

ISLAM

Vol. 4. No. 2 (2021) 89-102 $\quad$ E-ISSN: : 2723-4681

P-ISSN: 2722-2764

Published online on the journal's website: http://jurnal.iailm.ac.id/index.php/mutawasith

\section{Fenomena Praktik ljtihad dan Taqlid dalam Pandangan Hukum Islam}

\author{
Syarif Muhammad Yahya \\ Sekolah Tinggi Agama Islam Mahad Ali Cirebon, Indonesia \\ Syariff.muhdd@gmail.com
}

\begin{tabular}{|c|c|c|}
\hline Received: & Revised: & Published: \\
\hline 02-11-2021 & 17-11-2021 & 25-12-2021 \\
\hline \multicolumn{3}{|c|}{ DOI: https://doi.org/10.47971/mjhi.v4i2.352 } \\
\hline
\end{tabular}

\begin{abstract}
Abstrak
Tulisan ini bertujuan untuk menganalisis sejauh mana perspektif ijtihad dan taqlid menurut ulama klasik dan kontemporer. Memahami cakupan mujtahiddan muqallid syarat dan urgensinya dalam Fiqih Islam. Metode penulisan yang digunakan adalah metode kajian kepustakaan yang termasuk dalam kategori penelitian historis tekstual mengenai konten ijtihad. Sumber penelitian melalui data primer, sekunder, dan tertier yang diperoleh dari literatur, dokumentasi, dan pendapat para ahli. Hasilnya dapat disimpulkan bahwa prospek ijtihad pada era sekarang sebenarnya masih terbuka lebar bagi mereka yang memiliki kompetensi penuh, sayangnya masih cukup sulit direalisasikan dikarenakan beberapa kendala diantaranya satu, Banyak ulama yang beranggapan bahwa setelah kurun ke tiga pintu ijtihad telah tertutup, dan walaupun bisa maka kemungkinan berijtihad hanyalah pada level muqoyyad dan bukan mustaqil. Dua, Perbedaan prespektif tentang batasan-batasan objek ijtihad yang legal kerap menimbulkan konflik dan membuat para intlektual takut dan vakum. Tiga, Reaktualisasi hukum Islam masih sebatas wacana tanpa ada kesinambungan.
\end{abstract}

Kata Kunci: ljtihad, Taqlid, Hukum Islam

\begin{abstract}
Abstrct
This paper aims to analyze the extent of ijtihad and taqlid perspectives according to classical and contemporary scholars. Understanding the scope of mujtahid and muqallid requirements and urgency in Islamic Figh. The writing method used is a literature review method which is included in the category of textual historical research regarding the content of ijtihad. Sources of research through primary, secondary, and tertiary data obtained from literature, documentation, and expert opinion. The results can be concluded that the prospect of ijtihad in the current era is actually still wide open for those who have full competence, unfortunately it is still quite difficult to realize due to several obstacles including one, many scholars think that after the third period the door of ijtihad has been closed, and although it is possible, it is possible litihad is only at the level of muqayyad and not mustaqil. Two, the difference in perspective on the boundaries of the legal object of ijtihad often creates conflicts and makes intellectuals afraid and empty. Three, the actualization of Islamic law is still only a discourse without any continuity.
\end{abstract}


Keywords: ljtihad, Taqlid, Islamic Law

\section{A. PENDAHULUAN}

Landasan keilmuan dalam Islam dan Barat memang saling bertolak belakang, ketika di Barat ilmu beranjak dari satu premis kesangsian, maka dalam level wahyu, ilmu-ilmu keIslaman bersumber pada premis keyakinan (Alquran dan Hadis). Hal inilah yang menyebabkan pembicaraan secara akademik sering terhenti, lantaran sudah disekat oleh wahyu. Di dalam Islam, munculnya ilmu-ilmu keislaman adalah dalam rangka memahami wahyu untuk dipraktekan. Wahyu yang didalam wujudnya adalah Alqur'an dan Hadis yang sahih menjadi sumber utama ilmu-ilmu tersebut. ${ }^{1}$

Munculnya gerakan Allamadzhabiyyah (anti terhadap madzhab atau larangan bertaqlid pada mujtahid tertentu) yang digencarkan beberapa ulama klasik seperti Abu Dawud Addahiri, Syaukani dan kontemporer yang diwakili Nasirudin Albani, ${ }^{2}$ Muhammad Amin Senqiti, Abduh dan Muhammad lqbal menjadi sebuah kajian yang patut untuk ditelusuri validitasnya. Mengingat sebagian dari mereka dengan tegas mengharamkan taqlid dan menganjurkan seluruh umat Islam untuk melakukan istimbath secara langsung pada ayat Alqur'an maupun Hadis nabi dalam memahami dan mengamalkan Syariah Islam, seakan pintu ijtihad mutlak masih terbuka lebar bagi siapapun tanpa terkecuali. Hal ini menjadi sebuah tanda tanya besar ketika pada kenyataannya mayoritas umat Islam adalah orang awam pengamal salah satu madzhab tertentu.

Pada masa keemasan Islam, umat Islam tidak pernah sepakat untuk mengikuti satu madzhab tertentu. Hal ini di tegaskan oleh Abu Thalib al-Makki dalam Qauth Qulub, bahwasannya kitab dan karangan-karangan baru, ucapan serta fatwa tentang keharusan mengikuti satu madzhab, mengambil qaul ulama sampai dengan mempelajari detail madzhabnya adalah sesuatu yang tidak pernah ada pada masa abad pertama dan kedua Islam. ${ }^{3}$

Memasuki abad berikutnya, umat Islam mulai mengikuti madzhab tertentu yang digegas oleh para mujtahid, pada saat itu, jarang sekali orang yang tidak berpegangan pada satu madzhab fiqih dikarenakan sulitnya menempuh syarat untuk mencapai derajat mujtahid. ${ }^{4}$ Karenanya telah menjadi satu kesepakatan fuqaha bahwa seorang mujtahid boleh mecetuskan prespektifnya terhadap satu masalah hukum menurut ijtihadnya, dan

\footnotetext{
${ }^{1}$ Qodri Azizi, Pengembangan ilmu-ilmu Keislaman.Semarang. Aneka Ilmu, 2014, hal 12-13.

2 Seperti yang dikutip Buti dalam bantahanya terhadap Albani . Allamadzhabiyyah Akhtorul Bid'ah Tuhaddid as-syariah Islamiah. Beirut, Dar al-Farabi,tt hal, 17.

${ }^{3}$ Abu Thalib al-Makki, Qauth al-Qulub, juz I, (Cairo: Dar al-halabi, t.th), hlm. 124

${ }^{4}$ Waliyullah Ad-dahlawi, Al-inshof fi bayani Asbabil khilaf. Beirut. Dar Nafais, 2016, hal: 68
} 
hasil dari ijtihad tersebut bisa dijadikan pegangan syar'i yang wajib diikuti dan diamalkan oleh para pengikutnya. ${ }^{5}$

Ijtihad adalah suatu usaha darurat di dalam sejarah perkembangan syariah, karena ijtihad merupakan jalan untuk istinbath hukum dari dalil, baik yang naqli maupun yang aqli. Orang yang mempunyai kelengkapan syarat ijtihad ditugaskan mengistinbathkan hukum atas dasar fardlu kifayah. Sebagian ulama berkata, kita perlu membayangkan hal-hal yang mungkin terjadi lalu kita bahas hukumnya, agar ketika terjadi hal-hal itu hukum telah ada. Inilah jalan yang ditempuh oleh fuqaha ahli ra'yi dari golongan madzhab Hanafi. ${ }^{6}$

Berdasarkan latar belakang di atas, maka penelitian ini mencoba untuk untuk menganalisis sejauh mana perspektif ijtihad dan taqlid menurut ulama klasik dan kontemporer. Memahami cakupan mujtahiddan muqallid syarat dan urgensinya dalam Fiqih Islam.

\section{B. METODE}

Penelitian ini merupakan kajian kepustakaan (liberary research) yang termasuk dalam kategori penelitian historis tekstual mengenai ljtihad dan Taqlid pada masalah cabangcabang fiqih. Objek material dari penulisan adalah pikiran para tokoh yang terkait dengan ijtihad dan taqlid. Metode penelitian yang digunakan adalah metode deskriptif dan analisissintesis. Metode deskriptif digunakan, terutama, untuk mendata dan melakukan inventarisasi pemikiran para tokoh fiqh Syafi'i dan beberapa perspektif madzhab lainnya dengan membaca berbagai karya mereka sendiri. Sedangkan analisis-sintesis yang dimaksud adalah meneliti dan membaca secara kritis berbagai penjelasan para tokoh lintas madzhab pada tulisan mereka sehingga diperoleh pemahaman mendalam terkait fenomena ijtihad dan taqlid. Metode penelitian yang digunakan adalah metode kajian kepustakaan yang termasuk dalam kategori penelitian historis tekstual mengenai konten ijtihad. Sumber penelitian melalui data primer, sekunder, dan tertier yang diperoleh dari literatur, dokumentasi, dan pendapat para ahli.

\section{PEMBAHASAN DAN HASIL PENELITIAN}

\section{1. ljtihad}

\section{a. Pengertian ljtihad}

Ijtihad dalam bahasa Arab berarti mencurahkan segenap kemampuan untuk mencapai suatu hal atau perbuatan. Kata ijtihad hanya digunakan untuk hal-hal yang berat dan sulit. ${ }^{7}$

\footnotetext{
${ }^{5}$ Syatibi, Al-muwafaqot, Mesir, Rahmaniyyah, $t$, juz:4 hal 44.

${ }^{6}$ Muhammad Hasbi Ash-Shiddieqy, Pengantar Ilmu Fiqih, Semarang: Pustaka Rizki Putra,2014, hal. 202.

7 Wahbah Zuhaili, Ushul al-Fiqhi al-Islami, Beirut, Dar al-Fikr. 2011,hal: 1037
} 
ljtihad menurut ulama ushul fiqih adalah mencurahkan segenap kemampuan seorang faqih dalam mengistinbathkan hukum syariah' yang bersifat amaliah dari dalil-dalil yang terperinci. Sebagian ulama mendefinisikan ijtihad sebagai pencurahan segenap kemampuan dalam mengistinbathkan hukum dari dalil yang terperinci atau dalam menerapkannya. ${ }^{8}$

Dari definisi ijtihad tersebut maka bisa disimpulkan bahwa ijtihad terbagi menjadi dua, ljtihad tam dan ijtihad tatbiqi (aplikatif). ljtihad tam adalah wujud dari sebuah pencurahaan yang sempurna dalam hal istinbath hukum syariah dari dalilnya yang terperinci. Menurut mayoritas ulama, istinbathul hukmi seperti ini telah terputus dan tidak dipraktikan lagi oleh ulama mengingat keterbatasan malakah ${ }^{9}$ dan tertutupnya kemungkinan untuk berijtihad pada era sekarang.

Ijtihad tatbiqi atau aplikatif yaitu menerapkan hasil istinbath hukum ulama dulu dengan cara meneliti 'ilat hukum dari berbagai hukum kasuitik. Dengan cara ini, berbagai masalah hukum yang tidak dikenal pada zaman dulu dapat juga diketahui hukumnya. Karenanya tugas mujtahid tatbiqi adalah dengan metode anologi atau qiyas melalui cara tahqiq al-manath, yaitu menetapkan dan menjelaskan ada atau tidaknya ilat hukum pada satu kasus yang dihadapi berdasarkan ilat hukum yang telah diistinbathkan oleh mujtahid tam. ljtihad versi kedua inilah yang kerap menjadi perdebatan sengit di kalangan cendikia kontemporer seiring adanya perbedaan prinsip dan prespektif dalam menilai 'ilatul hukmi. ${ }^{10}$

\section{b. Kriteria Mujtahid}

Kriteria mujtahid dalam kajian ushul fiqih dibahas secara rinci dari berbagai aspek berbeda, mulai psikologi sampai penilaian kecerdasan intlektual seorang mujtahid yang harus memupuni. Kriteria inipun cenderung diprioritaskan untuk mujtahid tam saja yang keberadaannya sudah sangat langka. Kriteria tersebut adalah :

a) Manusia baligh, berakal memiliki malakah berupa kemampuan yang tertanam dalam jiwanya.

8. Abu Zahra. Ushul al-fiqh, Beirut, Dar al-kutub ilmiah, 2013 hal: 379

${ }^{9}$ Malakah yang dimaksud adalah bentuk dari keahlian yang tidak didapatkan melalui belajar maupun berguru, melainkan sebuah anugrah Allah swt yang melekat pada pribadi orang-orang tertentu yang ada semenjak masa kecil mereka.

10 Dalam bab Qiyas ada sepuluh cara menguji keabsahan ilat (maslakul ilat) sebagai sifat pada satu masalah hukum yang menjadi acuan ijtihad para Mujtahid, diantaranya adalah : Tahqiqul al-manath menetapkan wujudnya ilat yg samar dengan jalan ijtihad dalam satu kasus tertentu, Tanqihul al-manath : mencari ilat yang pas yang terdapat dalam hukum asal, Takhrijul manath : menentukan ilat yang tidak tertera dalam nas. Lihat : Zakariya Anshory. Ghoyatul wushul, Beirut, Darul Fikr 2014, hal 216, 223, 224. 
b) Menguasai ushul fiqih, untuk dapat berijtihad dengan benar seseorang harus menggunakan metode ijtihad tertentu yang diakui validitasnya. Metode ini terhimpun dalm ilmu ushul fiqih.

c) Menguasai ayat dan hadis-hadis hukum, baik secara bahasa, nahwu, sharaf, ma'ani, maupun syar'i.

d) Memahami dalil-dalil, baik yang naskh maupun mansyukh, masalah-masalah ljma, asbabun nuzul.

e) Menguasai hadis-hadis mutawatir, ahad, sahih, hasan dan dhaif. Keadaan para perawi hadis yang diterima dan tertolak. Dalam hal ini mujtahid boleh hanya berpegangan pada kitab-kitab standar ahli hadis kutubu sittah maupun tis'ah.

f) Menguasai bahasa Arab dan ilmu kebahasaan yang mendukungnya. Sebab Alqur'an dan hadis menggunakan bahasa Arab. Seseorang tidak dapat mengistinbathkan hukum dari sumber itu kecuali faham bahasa Arab guna mengetahui dilalah lafadz dari berbagai aspeknya.

g) Faqihun nafsi, yaitu orang yang mampu menangkap maksud syariat secara umum dalam istinbath hukum. ${ }^{11}$

\section{c. Tingkatan Mujtahid}

Ahli ushul fiqih mengelompokkan derajat fuqaha pada tujuh peringkat. Empat golongan termasuk kategori mujtahid, dan sisanya termasuk kategori taqlid. Kata taqlid disini dinisbatkan pada mereka yang memahami aturan hukum seorang mujtahid, dan bukan taqlid secara harfiah yang memiliki makna mengikuti tanpa tahu dalilnya. Ketujuh peringkat tersebut adalah: pertama, mujtahid mustaqil, yakni mujtahid yang secara mandiri merumuskan kaidah-kaidah yang dirumuskan sendiri dalam membangun fiqih di luar kaidah yang telah diketahui secara baku dalam beberapa madzhab. Mujtahid semacam ini menurut Suyuthi, tidak ada lagi. Bahkan kalau sekiranya orang meninginkan makatidak akan sanggup. Termasuk dalam kategori ini adalah imam-imam madzhab empat.

Kedua, mujtahid mutlaq ghairu mustaqil, yaitu orang yang memenuhi syarat untuk menjadi mujtahid mustaqil, namun tidak menciptakan kaidah-kaidah ijtihadnya sendiri, melainkan mengikuti kaidah imam madzhab tertentu. la tidak terikat, karena tidak bertaqlid tapi ia tidak mandiri karena masih mengunakan metode ijtihad imamnya. Seperti Abu yusuf dan Muhammad asaibani dari madzhab Hanafi, Buwaiti dan Az'farani dari madzhab Syafii.

Ketiga, mujtahid muqayyad, yaitu mujtahid yang terikat dengan madzhab imamnya, ia secara mandiri menetapkan kaidah-kaidah ushul namun tidak melampaui ushul dan kaidah imamnya. Seperti Abu Ishaq as-Sayrazi dan al-Mawardi dari madzhab Syafi'i. Mujtahid semacam ini juga disebut mujtahid madzhab atau mujtahid takhrij yang bertugas mensarikan

11 Wahbah Zuhaili, Ushul Fiqh, hal: 1044-1048 
kaidah dan menghimpun ketentuan-ketentuan umum pda fiqh madzhabnya. Mereka juga mengistinbatkan hukum yang tak ada nashnya.

Keempat, mujtahid tarjih adalah mujtahid yang mampu menarjih pendapat imam madzhabnya atas pendapat madzhab lain. Kelima, fuqaha tarjih, mereka adalah kelompok fuqoha yang memperbandingkan antara beberapa pendapat dan riwayat serta dapat memberikan penilaian terhadap pendapat imam yang lebih kuat. Keenam, Fuqaha al-Hafidz, yaittu mereka masuk kategori pentaqlid yang memiliki kemampuan ilmiah berdasarkan tarjih para pendahulunya, seperti para penulis kitab matan. Ketujuh, Fuqaha Muqallid, adalah fuqaha yang mampu memahami kitab-kitab, namun tidak memiliki kompetensi dalam mentarjih riwayat dan pendapat. Mereka hanya mengikuti pernyataan dalam kitab dan mengutipnya.kelompok ini yang yang paling banyak pada masa sekarang. ${ }^{12}$

\section{d. Hukum Berijtihad}

Seseorang jika memenuhi standar kriteria mujtahid baginya diharuskan (wajib 'aini) melakukan ijtihad untuk dirinya sendiri dalam berbagai masalah yang yang ada, dan haram untuk bertaqlid kepada mujtahid lain, kecuali jika keadaan mendesak dan tidak memiliki waktu untuk berijtihad. Selain itu, ijtihad merupakan satu keharusan bagi orang yang kompeten, jika masyarakat daerahnya membutuhkan hasil ijtihad dalam satu masalah yang dihadapi, sementara tidak ada orang lain yang sanggup ijtihad kecuali dirinya dan waktunya mendesak, jika waktunya tidak mendesak, maka ijtihad adalah fardlu kifayah baginya.

Ijtihad menjadi sunah ketika seseorang dihadapkan dengan masalah-masalah yang belum terjadi, baik berupa pertanyaan atau kejadian yang tidak terjadi pada waktu itu. ljtihad dihukumi haram ketikapada masalah tersebut terdapat nash yang qath'i dan jelas baik berupa Al-qur'an, Hadis maupun 'ijma. Selain itu, orang yang tidak memenuhi standar kriteria mujtahid juga haram melakukan ijtihad. ${ }^{13}$

\section{e. Objek ljtihad}

Dalam kitab mustashfa, ${ }^{14}$ Ghazali membatasi objek ijtihad hanya pada hukum-hukum syariah yang tidak memiliki nash qath'i. Adapun hukum yang memiliki nash qath'i baik ditinjau dari wurudun nash (kedatangannya) maupun dalalahnya, maka mujtahid tidak memiliki ruang sedikitpun untuk berijtihad didalamnya, seperti nash-nash yang menjelaskan kewajiban shalat lima waktu, puasa, zakat, haji, mengucap dua kalimat syahadat, keharaman zina, minum khamr dan lainnya.

Nash-nash dzhanni yang dijadikan objek para mujtahid terangkum dalam dua kriteria: pertama, hukum yang ada nashnya namun dzhanniyu dilalah, baik kedzhanniyan itu ditinjau

\footnotetext{
12 Abu Zahro ushul Fiqh... hal 389-399

${ }^{13}$ Ali Hasbullah, Ushul al-Tasri al-Islam. Beirut, Dar al-Marifah.tt hal. 96

${ }^{14}$ Al-Ghazali, al-Mustasfa min ilmil Ushul. Dar al-Kutub Ilmiyyah. 2016. Hal jilid II hal. 102
} 
dari kedatangannya saja maupun kedatangan dan dalalahnya, atau dalalahnya saja. Pekerjaan yang dilalui mujtahid dalam kajian ini adalah meneliti kebenaran dan akurasi sumbernya. Jika nash tersebut memiliki kriteria dzhanni dari kedatangannya seperti hadishadis ahad, dan membahas makna nash dan kekuatan dilalahnya terhadap makna, jika nash tersebut tergolong dzanni dilalah. Kedua, Hukum-hukum yang tidak disinggung nash dan ijma' ulama didalamnya. Disini mujtahid meninjau nash melalui dalil-dalil rasional seperti qiyas, istihsan, maslahat mursalah, syar'u man qablana dan dalil-dalil lain yang masih diperdebatkan. kajian inilah yang menyebabkan perbedaan yang luas antar ulama. ${ }^{15}$

Hukum yang diperoleh dari ijtihad hanya harus dipakai oleh mujtahid sendiri dan oleh orang yang meminta fatwa kepadanya, tak dapat dimestikan seseorang mengikuti dan melaksanakannya. Hukum yang diijtihadi tak dapat diyakini bahwa itu adalah hukum syara'. Hukum yang diperoleh dari ijtihad, merupakan hujjah bagi seseorang yang meminta fatwa, dan orang yang meminta fatwa itu tidak diharuskan untuk mengetahui dalilnya, karena mujtahid itu merupakan dalil bagi hukum itu sendiri. ${ }^{16}$

\section{Taqlid}

\section{a. Pengertian Taqlid}

Taqlid merupakan derivasi dari qallada yang berarti kalung. Kata taqlid menurut bahasa berarti memasang kalung di leher, misalnya taqlid al-hadyi berarti mengalungi leher hewan kurban. Taqlid menurut terminologi ushul fiqih adalah mengambil pendapat orang lain, kecuali Nabi Saw, tanpa mengetahui dalilnya. Hal ini disebut taqlid karena orang yang bertaqlid seakan-akan menjadikan hukum yang ditaqlidi itu seperti kalung di lehernya. ${ }^{17}$ Taqlid pada bidang furuiyyah seperti dalam masalah mengusap sebagian kepala dalam wudlu dan membaca qunut pada shalat subuh karena bertaqlid pada Imam Syafi'i, atau tidak membaca doa qunut dan mengaggap shalat sunat witir itu wajib karena bertaqlid pada Imam Abu Hanifah.

\section{b. Pembagian Hukum Taqlid}

Taqlid yang hukumnya haram dan disepakati oleh seluruh ulama memiliki tiga kriteria: pertama, tidak memperdulikan ayat Al-qur'an dan hadis, lantaran orang tua, masyarakat atau adat. Kedua, taqlid terhadap orang yang tidak kita ketahui, apakah orang itu mempunyai keahlian atau tidak. Ketiga, taqlid pada dalil yang bertentangan, tanpa melihat adanya nasakh-mansukh, aam khos, mutlaq muqayyad dan sebagainya. Taqlid hukumnya yang wajib adalah taqlid terhadap pendapat yang merupakan hujjah seperti ucapan Rasulullah SAW dalam uruf ulama salaf, taqlid seperti ini dinamakan ittiba'. Sementara taqlid yang

\footnotetext{
15 Ibid, hal. 103

16 Ibid.hal 163-164

17. Al- Syaukani, Al-qaul mufid fi hukmi al-Taqlid, Kuwait, Darul Qalam, 2016, hal. 265
} 
dibolehkan ialah menuruti pendapat para mujtahid dalam persoalan yang tidak kita ketahui dalam hukum Allah dan Rasul ${ }^{18}$

\section{c. Aspek-aspek Dasar Munculnya Taqlid}

Ada banyak sebab yang menjadikan orang-orang untuk menjadi muqallid dan hanya bergantung pada pendapat satu mujtahid tertentu, di antaranya adalah sebagai berikut:

a) Adanya seruan yang kuat yang dilakukan oleh para penyokong madzhab yang dianut, mereka menganggap orang yang tidak mengambilnya (taqlid) telah keluar dan berbuat bid'ah.

b) Melemahnya orang yang handal dalam peradilan. Para qadhi sebelum priode kelima dipilihkan dari ulama yang mampu melaksanakan istinbath hukum dari kitab Allah dan sunah Rasul.

c) Pembukuan fiqih madzhab oleh para penganut fanatiknya merupakan sebuah kesuksesan bagi setiap madzhab fiqih pada masa itu. ketika mayoritas ulama setelahnya berpegang pada kitab-kitab karangan mujtahid, mereka seakan tidak perlu membahas dan meneliti hal-hal baru.

d) Banyaknya ahli fiqih dan perbedaan yang yang terjadi satu sama lain. Bila mereka berfatwa maka fatwanya dibatalkan oleh pendapat ulama lain. Pembicaraannya tidak terhenti kecuali dengan mengetahui penjelasan masalah dari salah satu pendahulu mereka.

e) Rusaknya aturan pelajaran dan banyaknya ulama yang sibuk dengan hal-hal yang tidak bermanfaat yang tidak mengacu pada istinbath dan tidak mengikat pada satu sebab.

f) Terlalu banyak kitab-kitab yang telah membahas kajian hukum, sehingga membuat mereka merasa tidak perlu berijtihad.

g) Hilangnya rasa percaya diri, lemahnya keinginan dan menurunnya kehendak.

h) Cinta manusia terhadap materi yang menguasai dirinya dan beralihnya keinginan pada mengumpulkan harta. ${ }^{19}$

\section{Prespektif Ulama tentang Kewajiban ljtihad}

Terjadi tiga perbedaan prespektif para ulama terkait kewajiban ijtihad dan larangan bertaqlid. Kategori pertama adalah kelompok yang mewajibkan ljtihad bagi semua umat Islam, Abu Dawud Addahiri, Syaukani, Muhhammad As-Senqiti, dan Nasiruddin Albani secara

18 Muhammad Hasbi Ash-Shiddieqy, Pengantar Hukum Islam. Semarang: Pustaka Rizki Putra, 2014.hal. 141-142

${ }_{19}$ Muhammad Ali As-sayyis, Sejarah pembentukan dan perkembangan hukum Islam. Jakarta Akedemika Pressindo.(terj) 2014, hal, 180-182.

Syarif Muhammad Yahya 
tegas melarang untuk mengikuti madzhab tertentu, argumen kelompok ini adalah ayat Alquran :

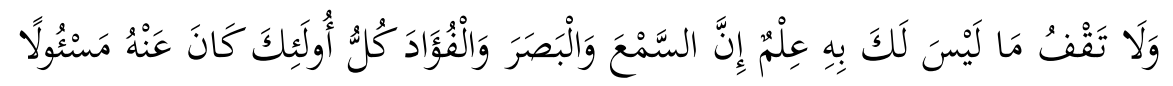

"Dan janganlah kamu mengikuti apa yang kamu tidak mempunyai pengetahuan tentangnya" (QS. Al-Isra: 36).

Syaukani menjelaskan terkait tafsir ayat ini, ilmu adalah mengetahui hal yang maklum apa adanya. Ketika prespektif ulama berbeda-beda dan bercabang maka darimana anda memahami ucapan orang yang anda ikuti itu benar, sedangkan yang lainnya salah sehingga menjadikan anda fanatisme terhadap satu madzhab, bukankah hal demikian menyalahi aturan, kenyataannya pada zaman sahabat, mereka tidak mengkultuskan pendapat sahabatsahabat tertentu.

Syaukani juga membantah dalil muqallid yang berargumen dengan ayat terkait kewajiban bertanya kepada Ahli dzikir (QS. an-Nahl:42), menurutnya, ayat ini tidaklah sesuai jika dijadikan pedoman dibolehkannya taqlid. Sebaliknya, makna ayat tersebut adalah hujjah atas dilarangnya taqlid jika ditelusuri dari beberapa aspeknya, diantaranya: pertama, dari aspek asbabun nuzul, ayat ini menjelaskan tentang jawaban atas orang-orang kafir Arab yang ingkar terhadap kerasulan Nabi Muhammad SAW. Hubungan ayat ini dengan kalimat sebelumnya menyatakan tentang pengutusan Rasulullah bagi masyarakat Arab.

Kedua, jika ayat itu difahami secara umum, maka tetap saja tidak pas untuk dijadikan dalil. Karena yang dimaksud Dzikir disitu adalah Alquran dan Hadis nabi, dan bukan ucapan mujtahid tertentu, pada hakikatnya ayat itu digunakan oleh muqollid untuk mengetahi pendapat imam-imamnya dan buka dzikir yang dimaksud. ${ }^{20}$

Kategori kedua, ijtihad tidak boleh dan taqlid itu wajib hukumnya setelah berlalunya masa-masa para imam mujtahid yang disepakati otoritas ijtihad mereka dan kebolehan bertaqlid kepada mereka. Prespektif inilah yang dianjurkan mayoritas ulama ushul kepada umat Islam secara umum. Karena pewajiban masyarakat awam untuk berijtihad merupakan pembenaran di luar batas kemampuan seseorang. Disamping berakibat pada lalainya tugastugas yang biasa mereka kerjakan dalam tatanan kehidupan bermasyarakat sementara waktunya akan tersita untuk belajar agar mencapai kemampuan ijtihad yang belum jelas hasilnya.

Said Ramadhan al-Buthi dalam Allamadzhabiyyahnya menganjurkan umat Islam untuk bermadzhab pada satu imam tertentu: al-madzhabiyyah adalah taqlidnya orang awam atau orang yang tidak memiliki kompetensi untuk berijtihad, kepada imam madzhab, baik

${ }^{20}$ Syaukani. Qaul mufid .... Hal. 3 
mengikuti satu madzhab atau pindah ke madzhab lainnya. ${ }^{21}$ Menurut Buti, pemahaman pengikut allamadzhabiyyah yang mengklaim memahami Al-qur'an dan Hadis secara langsung sangatlah sembrono, karena mereka meninggalkan taqlid kepada mujtahid sementara orang-orang awam yang tidak memiliki malakah sama sekali diwajibkan untuk berijtihad walaupun hanya sebatas membaca sumber dari kitab-kitab yang ada saja.

Al-Buthi kemudian mengutip perkataan salah satu ulamanya, Alhajandi, "jika seseorang ingin mencari dalil satu hukum, maka cukup bagi mereka membacanya pada kitab-kitab seperti Muwattha, Sahihain, Sunan Abi Dawud, dan Nasai. kitab-kitab itu sangant mudah didapatkan, jika kamu bias mencarinya dan menemukannya maka kamu tidak memiliki udzur (untuk taqlid), dan jika menemukan riwayat hadis Rasulullah yang berbeda-beda, maka dibolehkan bagimu untuk mengamalkan yang satu dan meninggalkan lainnya atau mengamalkannya secara bergantian". ${ }^{22}$ Jika demikan adanya maka apa yang ditegaskan oleh Buti tentang kewajiban bermadzhab merupakan solusi bagi masyarakat awam agar mereka tidak bermain-main dalam mengamalkan syariah Islam.

Prespektif ini juga tidak sepi dari kritikan, selain argumen yang telah disebutkan Syaukhani dan ulama yang pro terhadap ijtihad di atas. Larangan terhadap orang yang memiliki kemampuan berijtihad merupakan pembekuan potensi berfikir manusia dalam upaya mengembangkan ilmu pengetahuan maupun lainnya.

Pendapat ketiga, ijtihad bagi umat islam adalah perkara yang mubah, dan tidak wajib secara personal. Hanya saja mukallaf yang memiliki kompetensi berijtihad baginya diharuskan untuk melakukan ijtihad dan mengamalkan hasilnya dan tidak boleh bertaqlid. Adapun mereka yang tidak mampu maka baginya diharuskan mengikuti madzhab yang ada. Taqlid itu berbeda-beda sesuai perbedaan ihwal seseorang dalam kaitannya dengan sarana ijtihad. Sebab menuntut ilmu pengetahuan adalah termasuk fardlu kifayah. Kalau semua orang dilarang taqlid dan dituntut berijtihad, niscaya menuntut ilmu menjadi fardlu'ain.

Argumen demikian hanya akan merusak tatanan kehidupan orang banyak. Kalau semuanya taqlid, ijtihad pun batal dan kefardluan itu pun gugur. Dan terjadilah ta'thil (menyia-nyiakan) terhadapa syariat dan peniadaan terhadap ilmu. Karena itu ijtihad wajib atas salah satu dari sekelompok masyarakat. Allah berfirman:

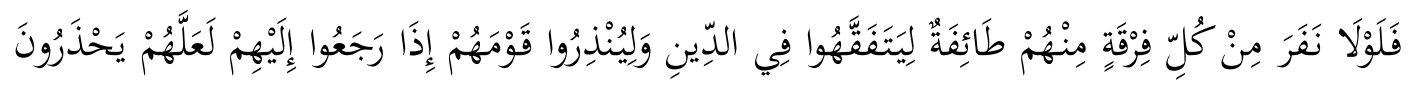

"Hendaklah sebagian dari tiap-tiap golongan diantra mereka memperdalam pengetahuan tentang agama untuk member peringatan kepada kaumnya, apabila mereka telah kembali kepadanya" (QS. at-Taubat: 122).

${ }^{21}$ Said Ramadan. Allamadzhabiyyah... hal: 17

22 Ibid, hal.18 
Semangat dari ayat di atas memiliki makna bahwa ijtihad tidak gugur dari semua kalangan, dan tidak merupakan perintah untuk semua. ${ }^{23}$

\section{Dhawabith Maslahah sebagai Landasan ljtihad}

Ijtihad secara umum bukanlah sebuah syariah yang harus ditempuh, paling jauh ijtihad hanya menyerupai tasyri'. jika dilihat dari sisi menjelaskan atas satu hukum yang masih samar maka ijtihad tidak identik dengan melahirkan dan menetapkan satu hukum baru, pada hakikatnya ijtihad hanya menjelaskan hukum Allah pada satu kejadian yang dinisbatkan pada seorang mujtahid dan muqallad-nya. Kesimpulan ini sesuai dengan anggapan ulama yang mengatakan bahwa adanya qiyas sebagai salah satu sumber syariah hanyalah alat untuk memunculkan hukum yang samar menjadi jelas dan bukan ihdast fi al-syariah mengada-ada hkum baru dalam syariah.

Tasyri' yang memiliki arti mencetuskan hukum-hukum agama dan semua yang berhubungan dengannya dari takhsis, taqyid bayanul mujmal adalah perkara yang tidak pernah ada kecuali pada era Rasulullah SAW, yang diambil dari Al-qur'an dan Sunah, dan hakim sesungguhnya adalah Allah SWT, tidak ada hakim selain-Nya. Pada waktu itu tugas Rasulullah SAW hanyalah penyampai amanat dan penjelas. ${ }^{24}$

Salah satu aspek penting dalam praktik ijtihad terhadap nash-nash qath'i baik Alqur'an maupun hadis mutawatir adalah dengan mendalami kajian dhawabith maslahah, batasan batasan maslahat yang telah disepakati ulama. Sebagai salah satu pakem yang membatasi ranah ijtihad, maslahat yang syar'i tidak akan bertentangan dengan nash. Maksud maslahat ini menurut Ghazali, ${ }^{25}$ bukanlah maslahat lahir semata, melainkan menjaga tujuan syariah yang terangkum dalam lima prinsip syariah, yakni: menjaga agama, menjaga jiwa, menjaga akal, menjaga nasab, dan menjaga harta.

\section{5. ljtihad dan Nash}

Nash jika dilihat dari dilalah terhadap makna dan hukumnya terbagi dua: pertama, nash qath'iyu tsubut wad dilalah: nash yang qath'i adalah nash yang memiliki kepastian dilihat dari pemiliknya, nash ini mencakup Al-qur'an dan hadis mutawatir. Adapun qath'i dilalah adalah nash yang memiliki arti tertentu dan tidak ada kemungkinan ta'wil atau makna lainnya, seperti ayat-ayat yang berhubungan dengan pembagian waris. Maslahat yang telah diafirmasi oleh syariah tidak akan bertentangan dengan nash qath'i. Merupakan sesuatu yang mustahil jika ada pertentangan antara nash qath'i yang menyebabkan adanya ketidaksempurnaan dan saling bertolak belakangnya nash qath'i.

\footnotetext{
${ }^{23}$ Assuyuti, Ar-rad ala man akhlad ilal alrd wa jahila annal ijtihad fikulli ash fardl.Beirut, Beirut: Darl Kutub ilmiah, 2014. hal: 68

24 Muhammad Ali Sayyis, Nasy'atu al fiqhul ijtihad wa tatowwurihi. Beirut, Majmaal Buhus Islamiyyah. 2014, hal.26-28

25 Al-ghazali. Mustasfha... juz 1, hal :286-287.
} 
Kedua nash dzhanni, nash yang menunjukkan pada makna tetapi terdapat kemungkinan ta'wil dan bisa dipalingkan pada makna lainnya, seperti kata al-quru' pada ayat kewajiban wanita yang sedang iddah (QS. al-Baqarah: 228). Pada kata al-quru' mujtahid boleh mengambil salah satu maknanya karena terkendalanya untuk menyatukan makna-makna yang berbeda. Hal ini dijelaskan oleh ulama ushul dalam bab mujmal.

Kata quru' tersebut jika dimaknai dengan pemahaman yang keluar dari madlul yang memiliki kemungkinan maslahat lain maka tidak dibolehkan. Dikarenakan termasuk ijtihad dalam batasaan nash yang qath'i. Hal ini seperti kejadian pertentangan antra nash qath'i dengan maslahat dimana maslahat akan selalu tunduk pada dalil qath'i. Tidak akan terjadi kemungkinan pertentangan antara dua dalil qath'i kecuali salah satunya di mansukh atau takhsis, karena setiap nash qath'i berfaidah untuk difahami dan diamalkan. ${ }^{26}$

Pergeseran makna ijtihad yang dipraktikan oleh cendikiawan muslim sekarang cenderung pada pemahaman liberal Sulaiman At-thufi, ${ }^{27}$ salah seorang pengikut madzhab Hambali yag menafikan ijma' demi sebuah maslahat yang diyakininya. Dengan dalih reaktualisasi hukum Islam, fenomena ini kembali dihidupkan beberapa cendikiawan Indonesia melaui tafsir-tafsir barunya misalkan kasus Munawir Sjadzali yang berijtihad membagi rata 1:1 laki-laki dan perempuan dalam hak warisan. Menurut Sjadzali, Al-qur'an memiliki kemungkinan ayat yang dihapus hukumnya (mansukh). Karenanya hukum ayat tentang pembagian 2:1 bisa dihapus juga. Hal ini didasarkan pada budaya dan adat Arab setempat, maka hukum tersebut dapat digugurkan oleh hukum yang sesuai dengan keadaan masyarakat sekarang (baru), seperti yang terjadi di Indonesia di mana wanita tidak lagi di bawah lindungan laki-laki sebab mereka sudah mampu bekerja sendiri. ${ }^{28}$

Prespektif Sjadzali dengan jelas menyalahi kaidah ushul la ijtihada ma'a wujudinnash tidak diperkenankan ijtihad pada permasalahan hukum yang telah dinash. Selain itu penghapusan hukum setelah Rasulullah wafat adalah sesuatu yang tidak valid (batil). Problem taghyir (perubahan) dalam syariah yang berkaitan dengan al-awaid asyariah berupa ketentuan-ketentuan umum yang lebih spesifik dan kongkrit seperti dalam hak pembagian waris ini tidaklah diperkenankan karena perubahan demikian otomatis mebatalkan ketentuan-ketentuan yang konstan dan kontiyu. ljtihad dengan cara demikian juga berorentasi pada ihdast fi al-syariah mengada-ada dalam syariah Islam.

Syathibi menganggap terjadinya legimitasi ihdast disebabkan karena tiga aspek: pertama, ketidaktahuan mujtahid atau mengabaikan tujuan hukum. Seseorang yang melakukan ihdast mungkin tidak mengetahui sarana yang menghantarkan pemahaman

\footnotetext{
${ }^{26}$ Abdul wahab Kholaf, Ushul fiqih Ilmu Ushul al-Fiqh, Beirut: Dar al-Qalam. 2015 , hal. 216

27 Said Ramdhan Buti, Dowabit Maslahah Fi as-Syariah al-Islamiyyah, Beirut, Ar-risalah. 2013 hal: 202

28 http://dorokabuju.blogspot.com/2012/03/munawir-sjadzali-reaktualisasi-hukum.html : Di akses pada 30 september 2021
} 
kepada tujuan itu, seperti tidak mengerti bahasa Arab dan tata bahasanya atau tidak tahu maksud itu sendiri.

Alasan kedua, ihdast terjadi sebab tahsin aldzhan bil aqli, memutuskan nilai sesuatu hanya berdasarkan pada spekulasi rasional semata. Ketiga adalah mengikuti hawa nafsu pribadi dalam usaha mencapai kebenaran. Dalam kondisi demikian, keinginan pribadi mendominasi bahkan menyembunyikan bukti-bukti yang benar dan menggiring pada kesimpulan-kesimpulan yang salah. ${ }^{29}$

\section{KESIMPULAN}

Berdasarkan uraian di atas, dapat disimpulkan bahwa prospek ijtihad pada era sekarang sebenarnya masih terbuka lebar bagi mereka yang memiliki kompetensi penuh, sayangnya masih cukup sulit direalisasikan dikarenakan beberapa kendala di antaranya: banyak ulama yang beranggapan bahwa setelah kurun ke tiga pintu ijtihad tertutup, dan walaupun bisa maka kemungkinan berijtihad hanyalah pada level muqayyad dan bukan mustaqil. Perbedaan prespektif tentang batasan-batasan objek ijtihad yang legal kerap menimbulkan konflik dan membuat para intlektual takut dan vakum. Reaktualisasi hukum Islam masih sebatas wacana tanpa ada kesinambungan. Makin maraknya generasi fanatik terhadap salah satu madzhab yang mengklaim kebenaran mutlak dan memusuhi argumen madzhab lainnya.

\section{Referensi}

Abu Zahrah, Muhammad. 2016. Ushul al-Fiqihm Mesir. Beirut: Dar al-Fikr al-Arabi. Ad-dahlawi, Waliyullah. 2016. Al-Inshaf fi Bayani Asbabil Khilaf. Beirut: Dar Nafais.

Al-buti, Muhammad Sa'id. 2013. Dowabit Maslahah Fi as-Syariah al-Islamiyyah, Bwirut. t.t.: Ar-risalah.

--------. t.th. Allamadzhabiyyah Akhtorul Bid'ah Tuhaddid as-Syariah Islamiah. Beirut: Dar al-Farabi.

Al-Ghazali, Abu Hamid. 2016. al-Mustasfhfa fi IIm al-Ushul. Beirut: Dar al-Kutub IImiyyah. Al-Syatibi, Abu Ishaq. t.th. al-Muwafaqat fi Ushul al-Ahkam. Beirut: Dar al-Marifah. Al-Zuhaili, Wahbah. 2011. Ushul al-Fighi al-Islami. Beirut: Dar al-Fikr.

Ash-Shiddiqy, Muhammad Hasbi. 2014. Pengantar Ilmu Fiqih. Semarang: Pustaka Rizki Putra. Asmin, Yudian. 2014. Filsafat Hukum Islam dan Perubahan Sosial. Surabaya: Al-Ikhlas.

As-Sayis. 2014. Nasy'atu al fiqhul ijtihad wa tathawwurihi. Cairo: Majmaal Buhus Islamiyyah. -------. 2014. Sejarah Pembentukan dan Perkembangan Hukum Islam: Jakarta Akedemika Pressindo.

As-suyuti, Abdurrahman. 2014. Ar-Rad ala Man Akhlad Ilal Alrd Wa Jahila Annal ljtihad Fikulli Ash Fardl. Beirut: Darl Kutub IImiah.

29 Yudian W Asmin, Filsafat hukum islam dan perubahan sosial (terj). Surabaya, Al-Ikhlas. 2014, hal.311 
Azizi, Qadri. 2014. Perkembangan Ilmu-ilmu Keislaman. Semarang: Aneka Ilmu. Hasbullah, Ali. t.th. Ushul al-Tasri al-Islam. Beirut. Beirut: Dar al-Marifah. Khallaf, Abdul al-Wahab. 2015. Ilmu Ushul al-Fiqh. Beirut: Dar al-Qalam. 